\title{
Sistem Informasi Penjualan Berbasis Web pada UD Dwi Surya Aluminium dan Kaca Yogyakarta
}

\author{
Fanny Fatma Wati', Uswatun Khasanah² \\ ${ }^{1}$ STMIK Nusa Mandiri/Ilmu Komputer \\ e-mail: fannyfatmawati8@gmail.com \\ ${ }^{2}$ Universitas BSI Bandung/Sistem Informasi \\ e-mail: 16170103@bsi.ac.id
}

\begin{abstract}
Cara Sitasi: Wati, F.F., \& Khasanah, U. (2019). Sistem Informasi Penjualan Berbasis Web pada UD Dwi Surya Aluminium dan Kaca Yogyakarta. Paradigma - Jurnal Komputer dan Informatika, 21(2), 149-156. doi:10.31294/p.v21i2.6026
\end{abstract}

\begin{abstract}
At this time the development of information technology is growing very rapidly. Directly or indirectly affect various aspects of life, including the business world. Almost all aspects have used computers as a tool to provide convenience for companies. UD Dwi Surya Aluminum and Glass Yogyakarta need an information system that support and provide satisfactory service for the customer. For that the author tries to make Thesis web-based sales information system on UD Dwi Surya Aluminum and Glass which until now has not been computerized. Sales system running on the UD is still conventional and data processing inside the UD is still manual, such as recording payment transactions and making reports that are still recorded in a book. The data storage in the book is considered less effective because of the data search process that takes a long time and often error recording due to human error. And Marketing of goods made UD Dwi Surya Aluminum and Glass around the scope of Yogyakarta. The design of the sales information system in this UD uses the waterfall method. With this sales website is the best solution to solve existing problems in this company, as well as with this system can improve sales service, especially on product offerings and facilitate in processing sales data that exist in the UD. A computerized system is better than a manual system, a sales system that is now more conducive than the previous system.
\end{abstract}

Keywords: Informasi System, Sales, Website

\section{PENDAHULUAN}

Pada saat ini perkembangan teknologi informasi berkembang dengan sangat pesat. Secara langsung atau tidak langsung berpengaruh terhadap berbagai aspek kehidupan, termasuk didalamnya dunia bisnis. Hal ini dapat dilihat terutama teknologi berbasis komputer dan internet. Hampir semua aspek telah menggunakan komputer sebagai alat bantu untuk memberikan kemudahan bagi perusahaan. Seperti halnya dalam perdagangan di dunia bisnis yang memerlukan data yang akurat untuk mendapatkan informasi dalam setiap kegiatannya. Kegiatan perdagangan yang sering dilakukan salah satunya adalahpenjualan barang. Media promosi yang digunakan masih terbatas sehingga dibutuhkan sebuah sistem informasi penjualan yang dapat menyelesaikan permasalahan yang ada.Dengan dibangunnya sistem penjualan online para pelaku bisnis atau usaha baik itu perusahaan menengah ke bawah atau perusahaan menengah ke atas dapat memanfaatkannya sebagai suatu media untuk mempromosikan perusahaannya serta produk- produk yang dimilikinya agar dapat dikenal lebih luas. Konsumen tidak perlu datang langsung ke toko untuk membeli sesuatu yang dibutuhkan, tetapi hanya dengan memesan barangdariinternet kemudian barang tersebut bisa diperoleh. "Internet dapat diartikan sebagai jaringan komputer yang luas dan besar yang mendunia, yaitu menghubungkan pemakai komputer dari negara ke negara di seluruhdunia" (Hastanti, Purnama, \& Wardati, 2015).

UD Dwi Surya aluminium dan kaca Yogyakarta merupakan salah satu toko yang menjual barangbarang seperti pintu, gerobak, etalase yang terbuat dari aluminium dan kaca. Sistem penjualan yang berjalan pada UD tersebut masih bersifat konvensional dan pengolahan data didalam UD tersebut masih manual, seperti pencatatan transaksi pembayaran dan pembuatan laporan yang masih dicatat dalam sebuah buku. Penyimpanan data dalam buku dinilai kurang efektif karena proses pencarian data yang membutuhkan waktu yang lama dan sering terjadi kesalahan pencatatan akibat human error. Serta Pemasaran barang yang dilakukan UD 
Dwi Surya Aluminium dan Kaca sekitar lingkupYogyakarta.Sehinggamembutuhkan sebuah sistem yang mampu meningkatkan pelayanan penjualan, terutama pada penawaran produk dan memudahkan dalam pengolahan data penjualan yang ada di UD tersebut.

\section{Tinjauan Pustaka}

a. Sistem Informasi

" Sistem informasi adalah sebuah yang bertujuan untuk menyimpan, memproses dan mengkomunikasikan informasi" (Hastanti et al., 2015).

b. Penjualan

"Penjualan merupakan sebuah proses dimana kebutuhan pembeli dan kebutuhan penjualan dipenuhi, melalui antar pertukaran informasi dan kepentingan" (Hanafiah \& Nusa, 2017).

c. Website

Website dapat diartikan sebagai kumpulan halaman - halaman yang digunakan untuk menampilkan informasi teks, gambar diam atau gerak, animasi, suara, atau gabungan dari semuanya itu baik yang bersifat statis maupun dinamis yang membentuk satu rangkaian bangunan yang saling terkait dimana masing - masing dihubungkan dengan jaringan - jaringan halaman (hyperlink)(Susanto \& Mariana, 2013).

d. BahasaPemrograman

1) Hypertext Markup Language (HTML)

HTML (Hyper Text Markup Language), yaitu suatu bahasa yang menggunakan tanda tanda tertentu (disebut sebagai Tag) untuk menyatakan kode - kode yang harus ditafsirkn oleh browser agar halaman tersebut dapat ditampilkan secara benar(Kusniawan \& Sardiarinto, 2016).

2) Preprocessor Hypertext (PHP)

PHP merupakan singkatan dari PHP Hypertext Preprocessor, PHP merupakan bahasa pemrograman skrip yang diletakkan dalam server yang biasa digunakan untuk membuat aplikasi web yang bersifat dinamis. Maksud web dinamis adalah dapat membentuk suatu tampilan web berdasarkan permintaan terkini, dapat dilakukan secara command line, yaitu skrip PHP dapat dijalankan tanpa melibatkan web server maupunbrowser (Wibowo, 2014).

3) Cascading Style Sheet(CSS)

"CSS (cascading style sheet) merupakan suatu bahasa program web yang digunakan untuk mengendalikan dan membanngun berbagai komponendalam web sehingga tampilan web akan lebih rapi, terstruktur dan seragam"(Chulkamdi \& Purnomo, 2016).

4) Javascript

"Javascript merupakan sebuah bahasa scripting yangdikembangkan oleh

Netscape"(Chulkamdi \& Purnomo, 2016). Untuk menjalankan script yang ditulis dengan javascript kita membutuhkanJavaScriptenabled browser yaitu browser yang mampu menjalankan JavaScript. Secara fungsional, javascript digunakan untuk menyediakan akses script pada objek yang dibenamkan (embedded). Contoh sederhana dari penggunaan javascript adalah membuka halaman pop up, fungsi validasi pada form sebelum data dikirimkan ke server, merubah image kursor ketika melewati objektertentu.

e. Software (Perangkat Lunak)

1) XAMPP Versi3.2.1

"XAMPP adalah salah satu paket instalasi apache, PHP, dan MySQL secara instant yang dapat digunakan untuk membantu proses instalasi ketiga produk tersebut"(Prayitno \& Safitri, 2015).

2) Framework

framework adalah kumpulan intruksi - intruksi yang dikumpulkan dalam class dan function function dengan fungsi masing - masing untuk memudahkan developer dalam memanggilkan tanpa harus menuliskan syntax program yang sama berulang - ulang serta dapat menghemat waktu (Destiningrum \& Adrian, 2017).

f. PhpMyAdmin

"phpMyAdmin juga dapat disebut sebagai tools yang berguna untu mengakses yang ada database MySQL server dalam bentuk tampilan web"(Tujni \& Megawaty, 2017).

g. Entity Relationship Diagram(ERD)

"ERD merupakan pemodelan data yang menggunakan entity dan relasi diantara entity tersebut" (Mulyani, 2016). ERD terbentuk dari komponen-komponen sebagai berikut:

1) Entitas atau objekdata

Kumpulan objek atau sesuatu yang dapat dibedakan atau dapat diidentifikasi secaraunik.

2) Relasi(Relationship)

Hubungan yang terjadi antara satu entitas atau lebih. Kumpulan relationship yang sejenis disebut relationship set.

3) Atribut atau elemendata

Karakteristik dalam entity atau relationship yang mengerjakan penjelasan detail tentang entity atau relationship, atau dengan kata lain adalah kumpulan elemen data yang membentuk suatu entitas.

4) Koneksi(connection)

Digunakan sebagai penghubung entitas yang membedakan entitas tersebut dengan entitas lainnya.

h. Logical Record Structure (LRS)

"LRS merupakantransformasidari penggambaran ERD dalam bentuk yang lebih jelas dan mudah untukdipahami”'(Andriansyah, 2016).

2. Analisa Sistem Berjalan

Activity sistem yang berjalan di UD Dwi Surya Aluminium danKacaYogyakarta adalah: 
a. Customer datang ke toko untuk memesan barang.

b. Bagian penjualan menulis pesanan customer, kemudian bagian penjualan menanyakan barang yang dipesan kepada bagiangudang.

c. Bagian gudang mengecek barang, jika tersedia maka barang akan dikirim oleh bagian pengirirman. Jika tidak tersedia digudang, maka bagian gudang memberikan perintah kepada bagian produksi untuk membuat pesanan barang. Setalah barang tersebut selesai dibuat, maka bagian pengiriman akan mengirim barang sesuai dengan alamat yang ada di nota penjualan.

d. Customer melakukan pembayaran kepada bagianpenjualan.

e. Bagian penjualan memberikan nota kepadacustomer.

f. Bagian penjualan membuat laporan penjualan yang diserahkan kepada pimpinan.

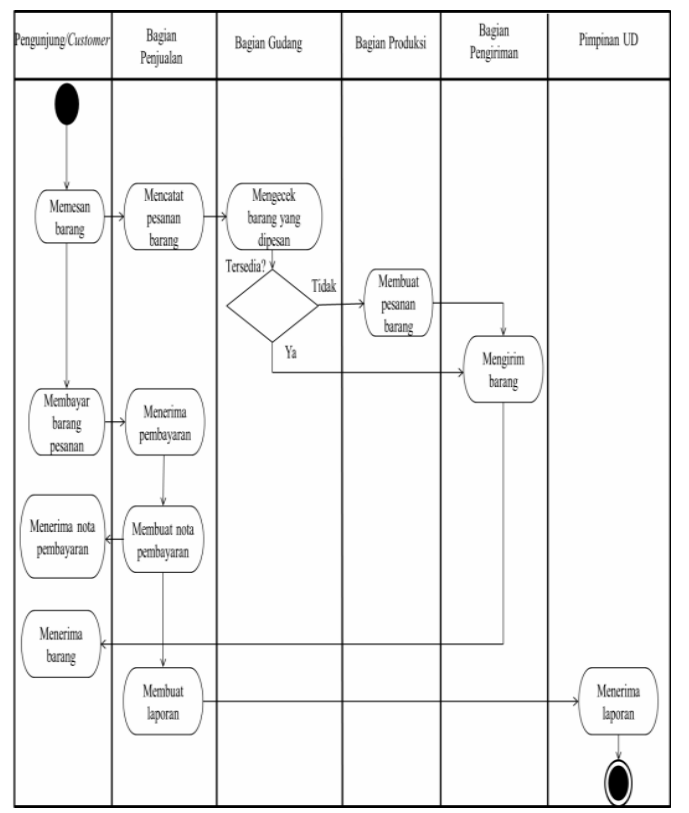

Gambar 1. Diagram Activity penjualan barang

\section{METODOLOGI PENELITIAN}

\section{Teknik Pengumpulan Data}

Metode penelitian yang digunakan dalam pengumpulan data yang digunakan dalam penulisan ini antara lain:

a. Observasi (Pengamatan)

Penulis melakukan pengamatan secara langsung untuk mengetahui prosedur sistem berjalan yang dilaksanakan pada UD Dwi Surya Aluminium dan KacaYogyakarta.

\section{b. Wawancara}

Penulis mengajukan beberapa pertanyaan secara lisan kepada Bpk Bayu selaku pemeilik tokoagar memperoleh data yang akurat.

\section{c. Studi Pustaka}

Penulis mengumpulkan data dan informasi yang berkaitan dengan perancangan sistem informasi akademik dari buku-buku, browsing di internet, serta mencari referensi-referensi lain yang berhubungan dengan sistem pendaftaran siswa baru

\section{Metode Pengembangan Sistem}

Metode penelitian yang digunakan dalam pengembangan sistem aplikasi sebagai berikut:

a. Analisa Kebutuhan (Requirment Analysis)

Proses pengumpulan kebutuhan dilakukan secara intensif untuk menspesifkasikan kebutuhan perangkat lunak agar dapat dipahami perangkat lunak seperti apa yang dibutuhkan oleh user. Spesifikasi kebutuhanperangkat lunak pada tahap ini perlu untuk didokumentasikan.

b. Design

Proses desain akan menerjemahkan syarat kebutuhan ke sebuah perancangan perangkat lunak yang dapat diperkirakan sebelum dibuat coding. Proses ini berfokus pada struktur data, arsitektur perangkat lunak, representasi, interface, dan detail (algoritma) procedural. Tahapan ini akan menghasilkan dokumen yang disebut software requirements. Dokumen inilah yang akan digunakan programmer untuk melakukan aktivitas pembuatan sistemnya.

c. Coding

Merupakan penerjemahan design dalam bahasa yang bisa dikenali oleh komputer. Dilakukan oleh programmer yang akan menterjemahkan transaksi yang diminta oleh user. Tahapan inilah yang merupakan tahapan secara nyata dalam mengerjakan suatu sistem. Dalam artian penggunaan komputer akan dimaksimalkan dalam tahapan ini.

d. Testing

Setelah pengkodean selesai maka akan dilakukan testing terhadap sebuah sistem yang telah dibuat. Pengujian ini berfokus pada pengetesan perangkat lunak secara logis dan fungsional dan memastikan bahwa semua bagian telah diuji. Hal ini dilakukan untuk meminimalisir kesalahan (error) dan memastikan keluaran yang dihasilkan sesuai dengan yang diinginkan.

e. Support/Maintenance

Pada tahapan ini tidak menutup kemungkinan sebuah perangkat lunak mengalami perubahan ketika sudah diberikan kepada user. Perubahan ini bisa terjadi karena adanya kesalahan yang muncul dan tidak terdeteksi saat pengujian atau perangkat lunak harus beradaptasi dengan lingkungan baru. Tahap pendukung/maintenance dapat mengulangi proses pengembangan mulai dari analisis spesifikasi untuk perubahan perangkat lunak yang sudah ada tanpa membuat perangkat lunak yang baru. 


\section{HASIL DAN PEMBAHASAN}

\section{Tahapan Analisis}

Sistem informasi penjualan berbasis web pada UD Dwi Surya Aluminium dan Kaca bertujuan untuk meningkatkan pelayanan penjualan, terutama pada penawaran produk dan memudahkan dalam pengolahan data penjualan yang ada di UD tersebut. Berikut ini spesifikasi kebutuhan dari sistem informasi penjualan berbasis web:

a. HalamanPengunjung

1) Pengunjung dapat melihat beranda website UDtersebut.

2) Pengunjung dapat melihat profil UD Dwi Surya Aluminium dan Kaca.

3) Pengunjung dapat melihat produk- produk yangdijual.

4) Pengunjung dapat melihat cara belanja dan carabayar.

5) Pengunjung dapat mendaftar sebagai member.

6) Pengunjung dapat login kehalaman memberjika sudah terdaftar.

7) Pengunjung dapat melihat keranjang belanja.

8) Pengunjungdapat melakukanchating online.

b. Halaman Member

1) Member dapat melakukan pembelian produk.

2) Member dapat melihat keranjang belanja.

3) Member dapat melakkan eidt profil.

4) Member dapat melakukan upload bukti.

5) Member dapat melakukan ganti password.

6) Member dapat mengisi testimoni.

7) Member dapat melakukan chating online.

c. Halaman Driver

1) Driver dapatmengupdate data pengiriman.

2) Driver dapat melakukan ganti password.

d. Halaman Admin

1) Admin dapat mengelola data admin.

2) Admin dapat mengelola datadriver.

3) Admin dapat mengelola datamember.

4) Admin dapat mengelola data produk.

5) Admin dapat mengelola data pengiriman barang.

6) Admin dapat mengelola datalaporanrealtime.

7) Admin dapat mengelola tampilanfrontend website.

8) Admin dapat melakukan gantipassword.
2. Rancangan Diagram

a.Use CaseDiagram

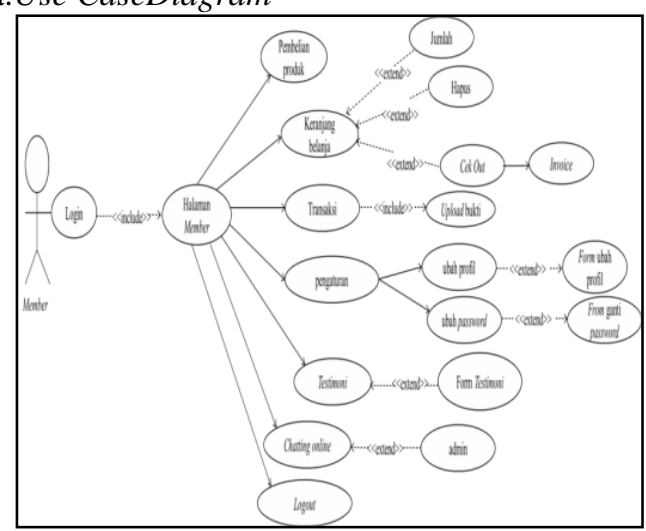

Gambar 2. Use Case Diagram Member

b. ActivityDiagram

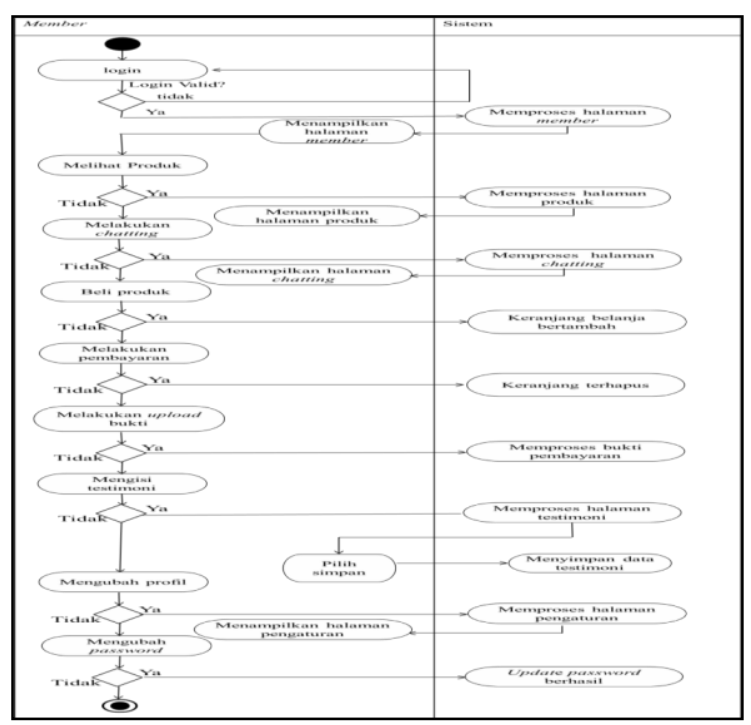

Gambar 3. Activity Diagram Member

c. Sequence Diagram

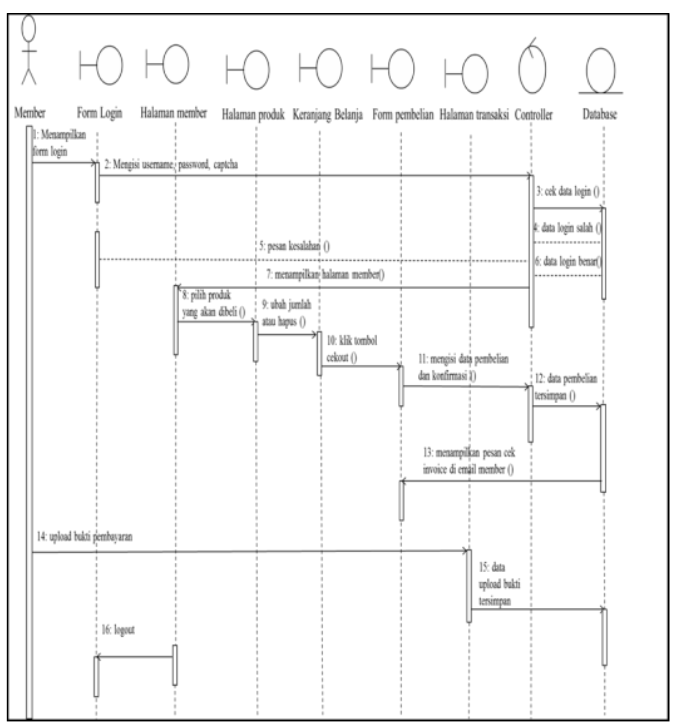

Gambar 4. Sequence Diagram 


\section{4..Class Diagram}

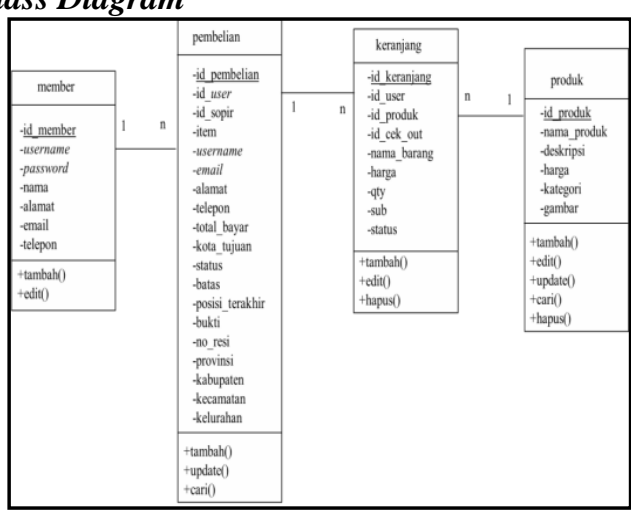

Gambar 5. Class Diagram

5. Deployment Diagram

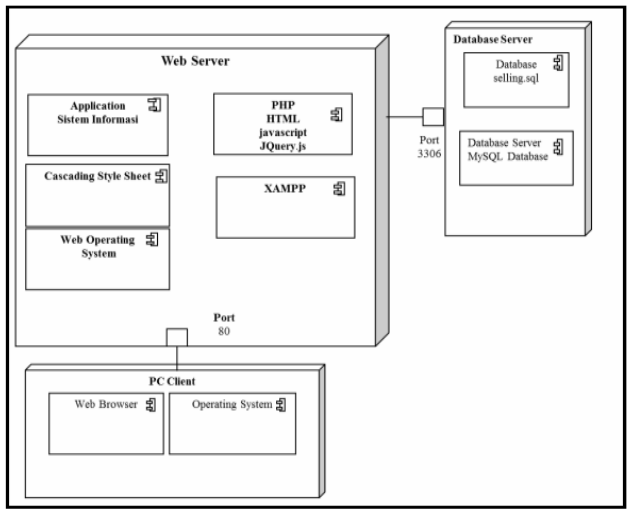

Gambar 6. Deployment Diagram

\section{Component Diagram}

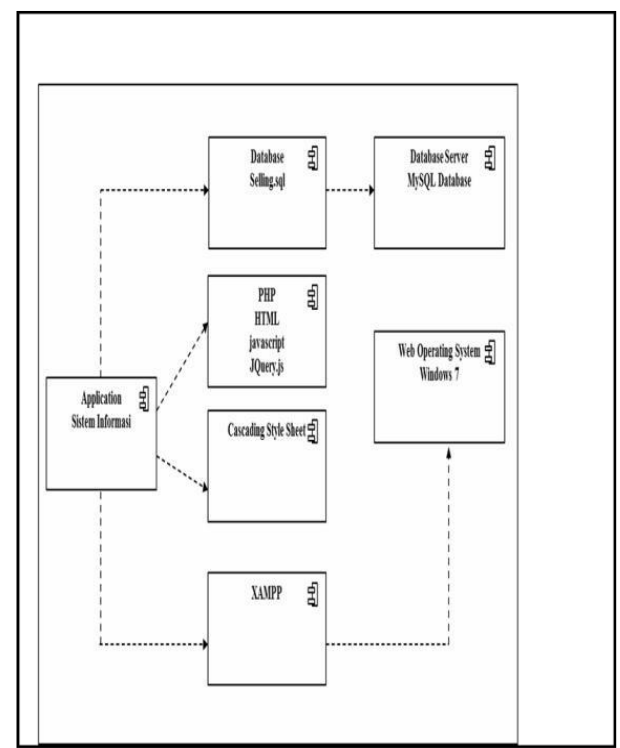

Gambar 7. Component Diagram
3. User Interface

a. Halaman Pengunjung

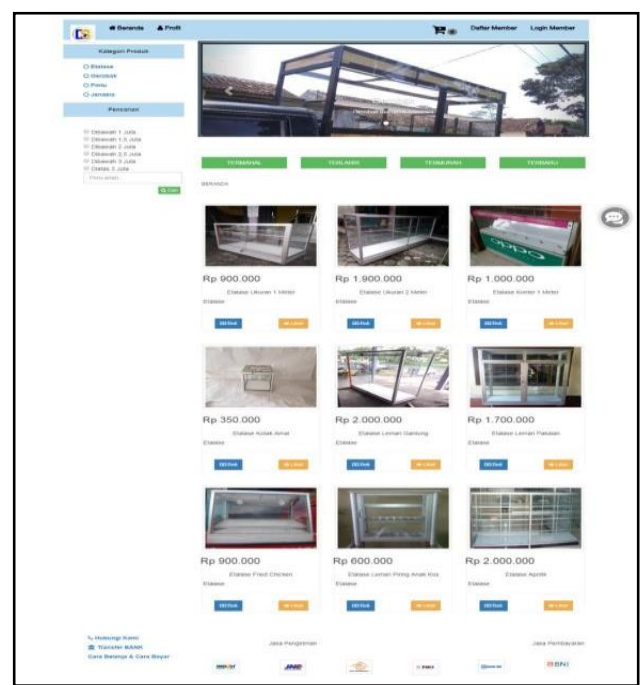

Gambar 8. User Interface Halaman Pengunjung

b. Halaman Cara Belanja dan Cara Bayar

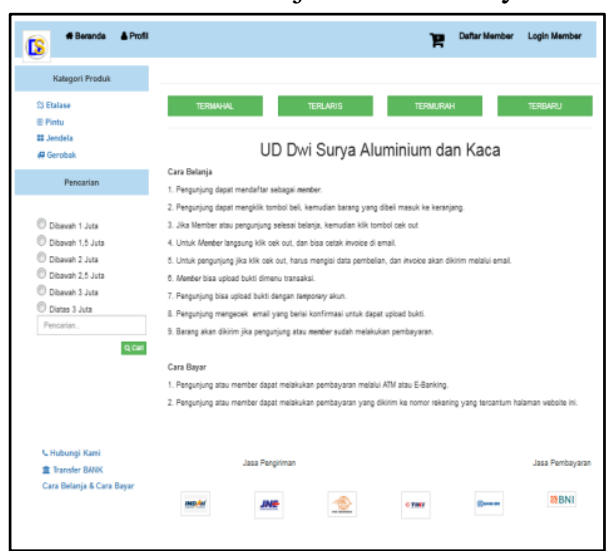

Gambar 9. Halaman Cara Belanja dan Cara Bayar

c. Halaman Daftar Member

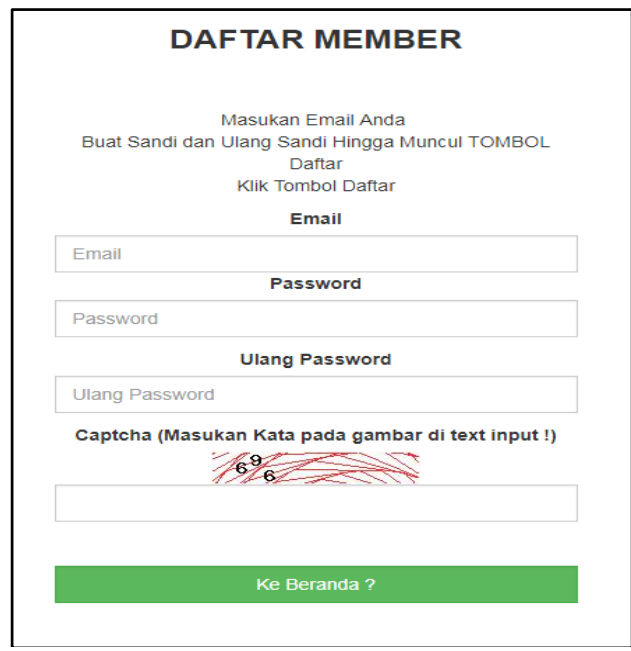

Gambar 10. Halaman Daftar Member 
4. Halaman Isi Data Pengunjung

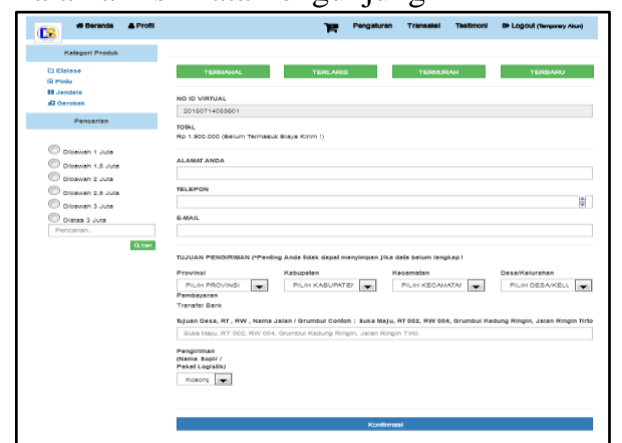

Gambar 11. Halaman Isi Data Pembelian Pengunjung

5. Halaman Login Member

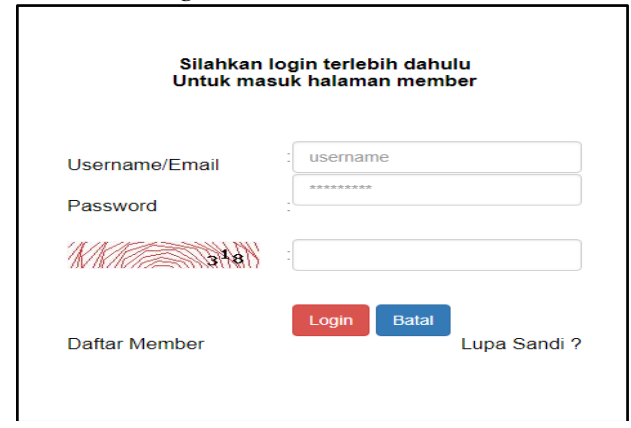

Gambar 12. Halaman Login Member

6. Halaman Member

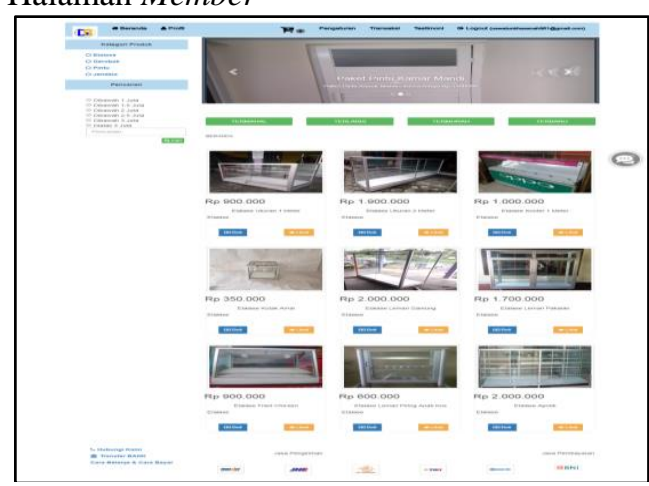

Gambar13. Halaman Member

7. Halaman Keranjang Belanja Member

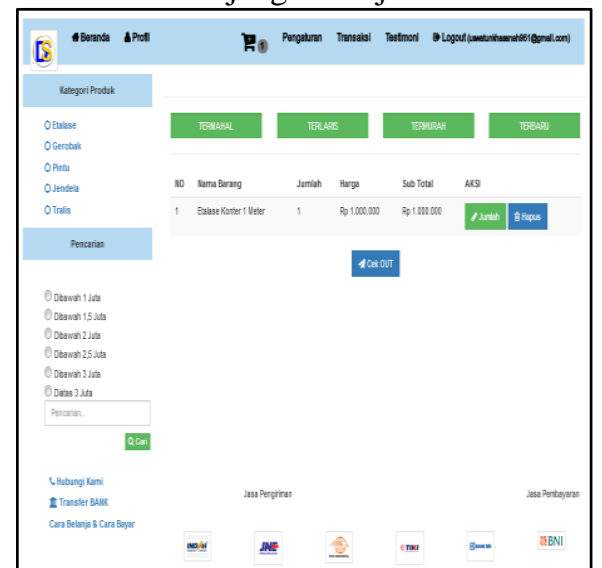

Gambar 14. Halaman Keranjang Belanja Member
8. Halaman Transaksi

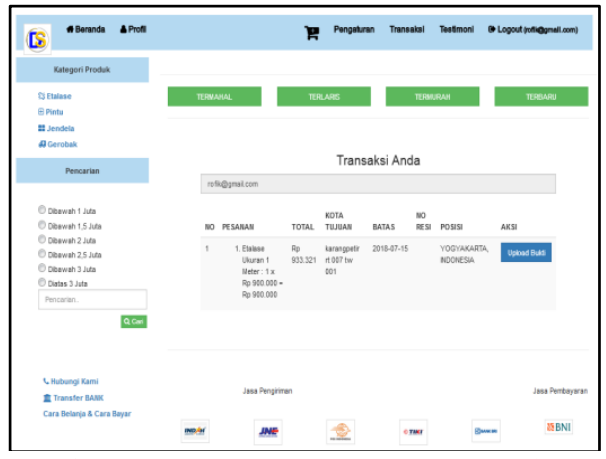

Gambar 15. Halaman Transaksi

9. Halaman Testimoni

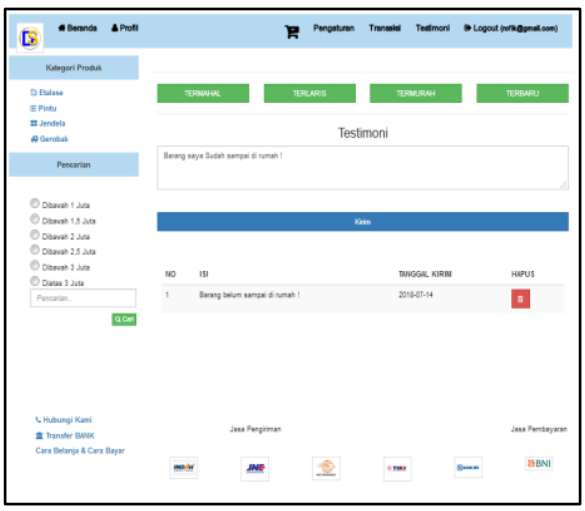

Gambar 16. Halaman Testimoni

10. Halaman Pengaturan Member

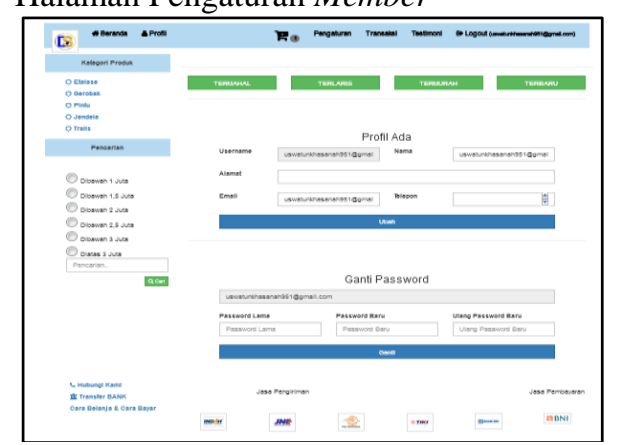

Gambar 17. Halaman Pengaturan Member

11. Halaman Submenu AturDriver

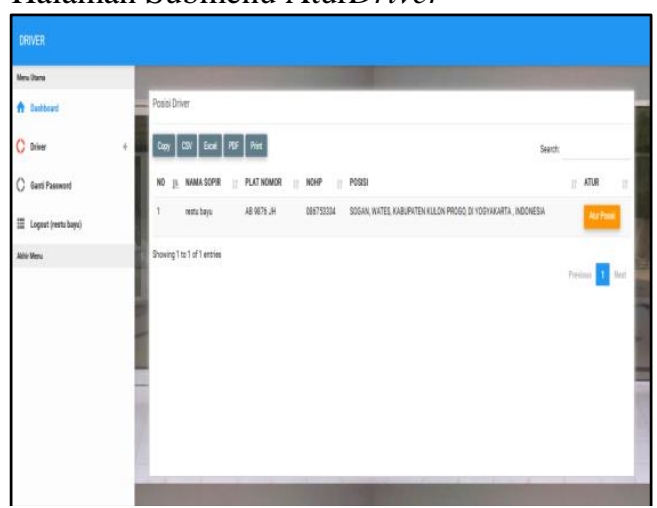

Gambar 18. Halaman Submenu Atur Driver pada Halaman Driver 
12. Halaman Submenu PosisiBarang pada

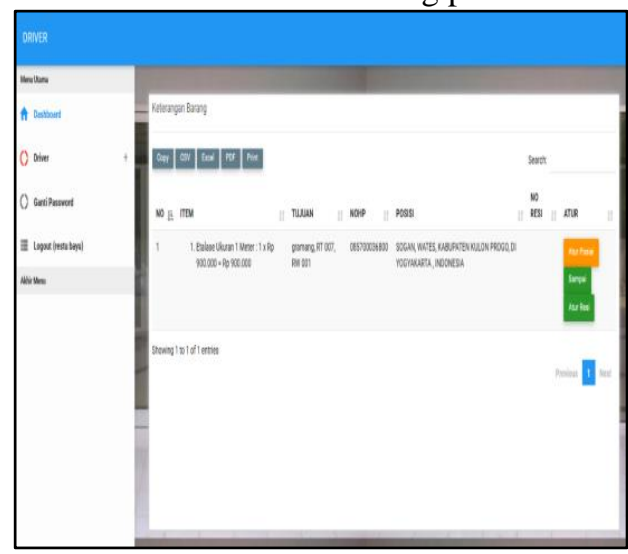

Gambar 19. Halaman Submenu PosisiBarang pada Halaman Driver

13. Halaman Menu Ganti Password pada Halaman Driver

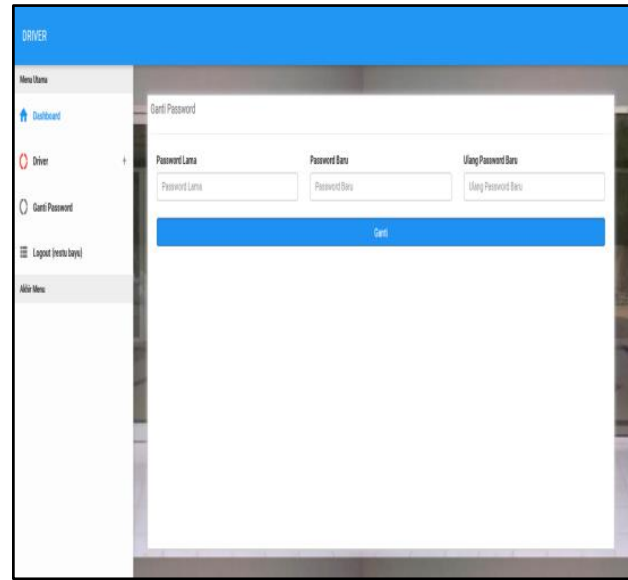

Gambar 20. Halaman Menu Ganti Password pada Halaman Driver

\section{Halaman Menu Dashboard}

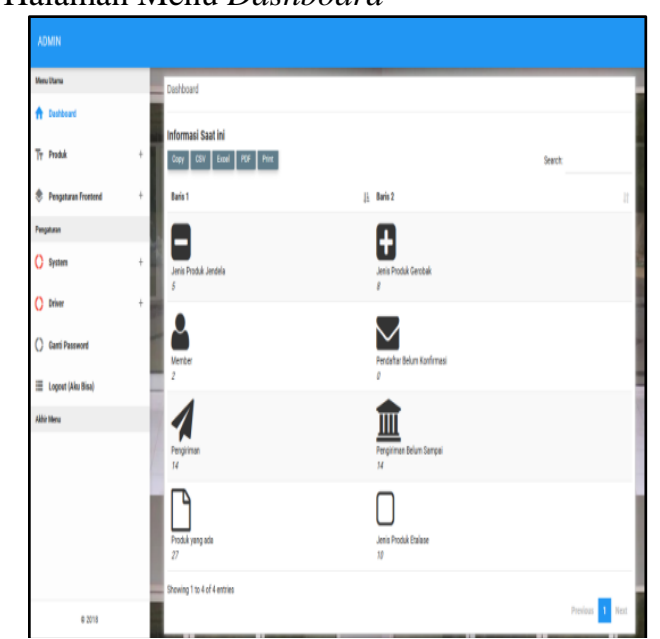

Gambar 21. Halaman Menu Dashboard pada Halaman Admin
15. Halaman Menu Produk pada Halaman Admin

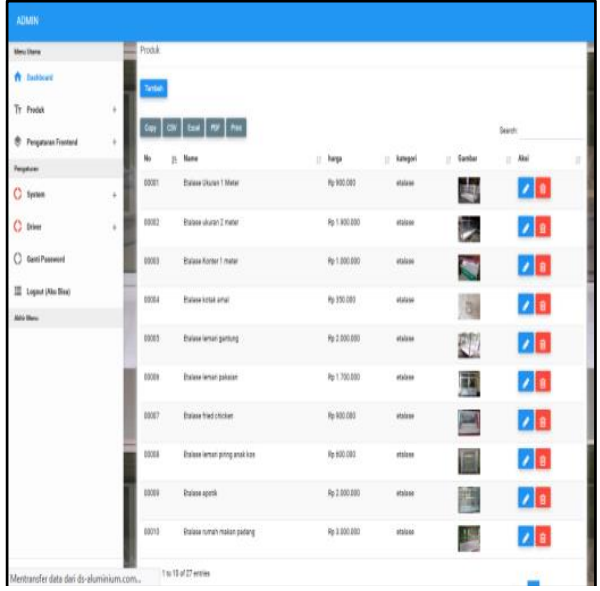

Gambar 22. Halaman Menu Produk pada Halaman Admin

16. Halaman Submenu Pengiriman

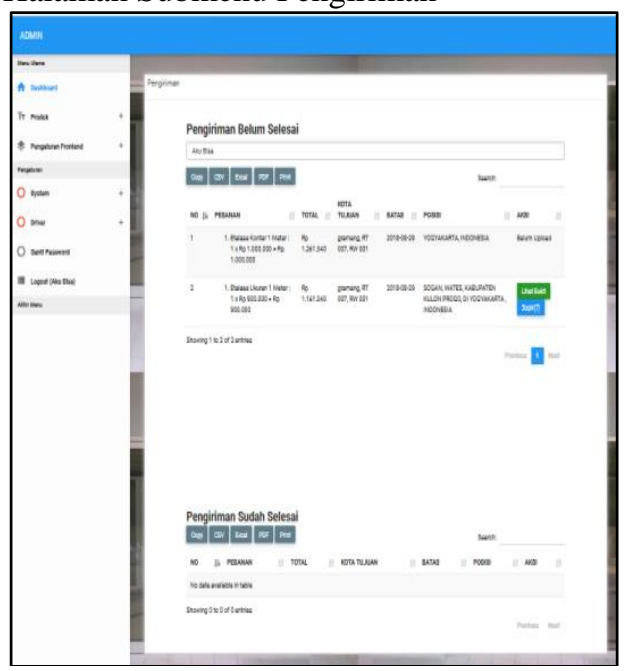

Gambar 23. Halaman Submenu Pengiriman pada Halaman Admin

17. Halaman Submenu Admin

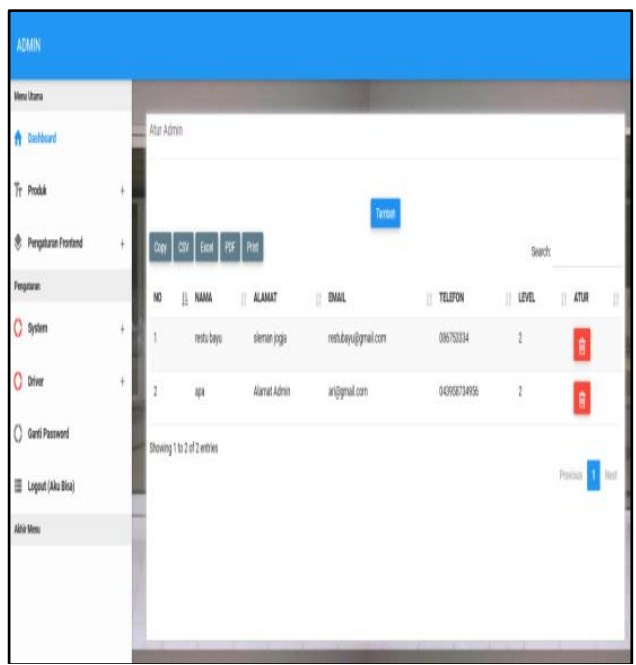

Gambar 24. Halaman Submenu Admin 


\section{KESIMPULAN}

Dengan adanya sistem penjualan online berbasis web dapat mempermudah dalam melakukan pembelian tanpa adanya batasan waktu dan dapat menjangkau seluruh wilayah. Sistem informasi penjualan online berbasis web ini dapat mengurangi baiaya yang dikeluarkan untuk promosi dan pemasaran produk serta dapat mempermudah dalam pengolahannya seperti update data.

\section{REFERENSI}

Andriansyah. (2016). Sistem Informasi Pendaftaran Event dengan PHP untuk Panduan Skripsi. Jawa Barat: CV.ASFA Solution.

Chulkamdi, M. T., \& Purnomo, S. (2016). Perancangan Dan Implementasi Game Interaktif Pengenalan Huruf Dan Angka Untuk Media Pembelajaran Di Paud Wachid Hasyim Ponggok Kabupaten Blitar. Antivirus : Jurnal Ilmiah Teknik Informatika, 10(1), 21-31. https://doi.org/10.35457/antivirus.v10i1.84

Destiningrum, M., \& Adrian, Q. javar. (2017). Sistem Informasi Penjadwalan Dokter Berbassis Web Dengan Menggunakan Framework Codeigniter (Studi Kasus: Rumah Sakit Yukum Medical Centre). Jurnal Teknoinfo, 11(2), 30-37. Retrieved from http://ejurnal.teknokrat.ac.id/index.php/tekn oinfo/article/view/24

Hanafiah, H. S., \& Nusa, A. A. F. (2017). Rancang bangun sistem informasi penjualan, pembelian dan persediaan suku cadang pada bengkel tiga putra motor garut. Jurnal Infotronik, 2(2), 107-115. Retrieved from http://jurnal.usbypkp.ac.id/index.php/infotroni k/article/download/37/37

Hastanti, R. P., Purnama, B. E., \& Wardati, I. U. (2015). Sistem Penjualan Berbasis Web (ECommerce) pada Tata Distro Kabupaten Pacitan. IJurnal Bianglala Informatika, 3(2), 1-9. https://doi.org/10.1007/s13226-018-02845

Kusniawan, A., \& Sardiarinto. (2016). Perancangan Website Jasa Desain Interior Sebagai Media Pemasaran Studi Kasus: CV. Focalpoint Interior. Jurnal Evolusi Volume, 4(2), 1-10. Retrieved from http://ejournal.bsi.ac.id/ejurnal/index.php/evol usi/article/download/694/570.
Mulyani, S. (2016). Sistem Informasi Manajement Rumah Sakit. Bandung: Abdi Sistematika.

Prayitno, A., \& Safitri, Y. (2015). Pemanfaatan Sistem Infromasi Perpustakaan Digital Berbasis Website Untuk Para Penulis. IJSE Indonesian Journal on Software Engineering, l(1), $1-10$. https://doi.org/10.4028/www.scientific.net/A MR.756-759.138

Susanto, A., \& Mariana, N. (2013). Rancang Bangun Sistem Informasi Penjualan Aksesoris Hanphone Berbasis Web Pada Dazzle Cellular Semarang. Jurnal Dinamika Informatika, 5(1), 1-6. Retrieved from http://lppm3.bsi.ac.id/jurnal/index.php/evo/ article/view/234

Tujni, B., \& Megawaty. (2017). Pelatihan Pembuatan Web Dengan Php Pada Smp Negeri 27 Palembang. Abdimas Mandiri, 1(1), 37-40. Retrieved from http://ejournal.uigm.ac.id/index.php/PGM/arti cle/view/288/291

Wibowo, A. (2014). Pembuatan Sistem Informasi Penjualan Furniture Dan Electronic Pada Toko Joice Group. Indonesia Journal on Netwoking and Security, 3(4), 35-43. Retrieved from http://ijns.org/journal/index.php/ijns/article/ view/350/344

\section{PROFIL PENULIS}

\section{Penulis Pertama}

Nama Saya Fanny Fatma Wati, saya berasal dari Jawa Tengah tepatnya daerah Bogangin Kecamatan Sumpiuh Kabupaten Banyumas.. Saya lahir di Banyumas tanggal 08 Mei 1996. Riwayat singkat pendidikan saya lulusan MA Negeri Sumpiuh (2014), D3 AMIK BSI Purwokerto (2017), S1 Universitas BSI Bandung (2018) dan sekarang saya sedang menjalani pendidikan S2 di STMIK Nusa Mandiri Jakarta Semester 2.

\section{Penulis Kedua}

Nama Saya Uswatun Khasanah, Alamat saya Desa Karangpetir Kecamatan Tambak Kabupaten Banyumas Jawa tengah. Saya lahir pada tanggal 15 April 1996. Riwayat singkat pendidikan saya MA Negeri Sumpiuh (2014), D3 AMIK BSI Purwokerto (2017), S1 Universitas BSI Bandung (2018) . 